\title{
O USO DA INFORMAÇÃO CONTÁBIL PELAS ORGANIZAÇÕES DO TERCEIRO SETOR: PRÁTICAS DE CONTABILIDADE DAS FUNDAÇÕ̃ES DE APOIO DAS UNIVERSIDADES PÚBLICAS DA REGIÃO SUL DO BRASIL
}

\author{
THE USE OF ACCOUNTING INFORMATION FOR NONPROFIT ORGANIZATIONS: \\ ACCOUNTING PRACTICES OF FOUNDATIONS SUPPORT OF PUBLIC UNIVERSITIES \\ IN SOUTHERN BRAZIL
}

Ricardo Adriano Antonelli ricardoaantonelli@yahoo.com.br Universidade Tecnológica Federal do Paraná

\author{
Sônia Maria Augustinho \\ soniam@utfpr.edu.br \\ Universidade Tecnológica Federal do \\ Paraná
}

\author{
Vicente Pacheco \\ vpacheco@ufpr.br \\ Universidade Federal do Paraná
}

\begin{abstract}
RESUMO: A transparência nas relações intermediadas pelas fundações de apoio às universidades públicas brasileiras é questionada por recentes investigações. Sendo a contabilidade ferramenta indispensável à transparência da gestão das organizações, o objetivo desta pesquisa é evidenciar as práticas de contabilidade das fundações de apoio das universidades públicas brasileiras. O estudo se valeu da análise documental e pesquisa de campo a partir da aplicação de questionário estruturado nas fundações das universidades públicas da região sul do Brasil. Os dados foram tratados com as técnicas estatísticas de análise descritiva, univariada e comparação de médias. Como resultado, observa-se que as informações contábeis são utilizadas pelas fundações preferencialmente para fins fiscais e controle das operações, enquanto o planejamento e o orçamento são utilizados por $90 \%$ das fundações, os custos são calculados por apenas $40 \%$ dessas organizações, revelando o uso primordial da contabilidade para atender aos ditames da legislação e as normas impostas por seus financiadores.
\end{abstract}

Palavras-chaves: Contabilidade. Organizações do Terceiro Setor. Fundações de Apoio.

ABSTRACT: Transparency in relationships brokered by the foundations to support Brazilian public universities is questioned by recent research. Being the indispensable tool for accounting transparency of organizational management, the objective of this research is to highlight the accounting practices of the foundations supporting the Brazilian public universities. The study made use of document analysis and field research from the application of a structured questionnaire he foundations of public universities in southern Brazil. The data were treated with the use of statistical descriptive and univariate analysis and comparison of averages. As a result, it is observed that the accounting information is used by the foundations preferably for tax purposes and control of operations, while planning and the budget are used by $90 \%$ of the foundations, the costs are calculated for only $40 \%$ of these organizations, revealing the primary use of accounting to meet the dictates of the law and the rules imposed by their lenders.

Keywords: Accounting. Nonprofit Organizations. Support Foundations. 


\section{INTRODUÇÃO}

As entidades sem fins lucrativos têm atuações voltadas para finalidades públicas e coletivas, no sentido de auxiliar a geração do bem comum, as quais compõem de acordo com uma tipologia organizacional, o chamado terceiro setor, sendo que o primeiro e o segundo abrangem o Estado e o mercado, respectivamente (ALVES e SLOMSKI, 2006).

Segundo Miranda (2009) as Organizações do Terceiro Setor (OTS) não estão interessadas em lucratividade, mas sim em permanência. Nesse sentido, Cunha e MatiasPereira (2012) enfatizam que as OTS buscam a sua continuidade, assim como reza as bases conceituais da contabilidade para todas as entidades.

Sendo o patrimônio o objeto da contabilidade, onde existe um patrimônio a ser administrado, esteja ele vinculado a pessoa física ou jurídica, com ou sem fins lucrativos, a contabilidade com seus conhecimentos teóricos e práticos sempre estará presente (LAFFIN, BORBA e CRUZ, 2002).

Dentre as diversas modalidades de organizações abrigadas sob o caráter de OTS, inserem-se as fundações de apoio às instituições públicas de ensino superior, entidades organizadas por pessoas dispostas a colaborar com a produção e disseminação do conhecimento em apoio à missão das universidades (COELHO e COELHO, 2006).

Aníbal et al. (2015) em uma série de reportagens realizadas em cinco estados brasileiros (Rio de Janeiro, São Paulo, Paraná, Santa Catarina e Rio Grande do Sul), colocaram em discussão a transparência das fundações de apoio. Segundo os autores há falta de transparência nas relações intermediadas pelas fundações de apoio. Nesse sentido, Castro et al. (2014) registram que tem-se a contabilidade como ferramenta indispensável para aumentar a transparência da gestão.

Embora Alves e Azevedo (2007) ponderem: que as fundações de apoio tornaram-se comuns no interior das universidades públicas no Brasil; que é cotidiano o debate da comunidade acadêmica em relação aos benefícios ou prejuízos dessas para a esfera pública, e; que tratar especificamente das fundações de apoio é assunto relevante e controvertido, não foram encontradas pesquisas relacionadas às práticas contábeis adotadas por essas organizações.

Castro et al. (2014) ao estudarem as características das publicações nacionais que discutem o uso da contabilidade nas instituições do terceiro setor, no período de 2004 a 2013, constataram que apesar do interesse da academia nas pesquisas relacionadas à aplicação da contabilidade e dos instrumentos contábeis em apoio a gestão nas OTS, o seu uso nessas entidades ainda é restrito.

Assim, a fim de esclarecer se as conclusões de estudos relacionando contabilidade e OTS se restringem àquelas organizações objeto das pesquisas e se suas conclusões podem ser generalizadas para as fundações de apoio, coloca-se como pergunta norteadora para esta pesquisa: Quais são as práticas de contabilidade das fundações de apoio a instituições públicas de ensino superior no Brasil?

No intuito de responder a essa questão opta-se neste artigo por replicar, parcialmente, o estudo de Santos (2010), cujo objetivo geral foi evidenciar as práticas de contabilidade das organizações sem fins lucrativos da cidade de Curitiba, Paraná.

Para Laffin, Borba e Cruz (2002) a observação pormenorizada sobre os eventos contábeis ocorridos no patrimônio das OTS decorre, sobretudo, de uma responsabilidade 
comprometida com o patrimônio das entidades e de suas consequências no âmbito da sociedade.

Desta forma, considera-se de interesse social estudar as práticas contábeis das fundações de apoio a instituições públicas de ensino superior no Brasil. Por fim, vislumbra-se a perspectiva de contribuição acadêmica cumulativa ao tema em razão do estudo centrar-se em entidades cujas práticas contábeis ainda não foram investigadas em conjunto.

\section{REFERENCIAL TEÓRICO}

\subsection{As Fundações de Apoio a Instituições Públicas de Ensino Superior}

Salomon e Anchier (1996), relacionando a metodologia de identificação da Organização das Nações Unidas (ONU), ensinam que as organizações sociais sem fins lucrativos possuem cinco características cruciais: (i) organização, ou seja, possui uma realidade institucional e uma estrutura organizacional interna; (ii) é privada, sem vinculação institucional com o governo; (iii) não faz distribuição de lucros; (iv) se autogoverna e (v) possui algum grau de participação voluntária.

No que concerne especificamente ao caso brasileiro, o código civil (Lei $\mathrm{n}^{\mathrm{o}}$ 10.406/02) em seu artigo 40, segrega as pessoas jurídicas em dois grupos: (i) direito público (União, Estados, Distrito Federal, Municípios, autarquias e outras entidades criadas por lei, como as fundações públicas e agências reguladoras); e (ii) direito privado (associações, fundações, sociedades, organizações religiosas e partidos políticos).

Com isso, observa-se que as formas jurídicas legais das OTS no Brasil são essencialmente associações e fundações. Silveira (2007) assinala a diferença essencial entre associações e fundações: a primeira possui finalidade coletiva, de interesse de seus associados, enquanto as fundações possuem finalidade pública.

Reforçando essa afirmação, Santos (2008, p. 50) afirma que as fundações se revestem de caráter público na medida em que se dedicam a causa e problemas sociais por meio de mecanismos delineados pelos seus instituidores.

Nessa realidade inserem-se as fundações de apoio a instituições públicas de ensino superior, pessoa jurídica de direito privado, instituída por particulares, com seus próprios recursos, conforme disciplina o artigo 62 do Código Civil de 2002.

O Ministério da Educação (2014) assinala que as fundações de apoio foram criadas com a finalidade de apoiar projetos de pesquisa, ensino, extensão e de desenvolvimento institucional, científico e tecnológico, de interesse das instituições de ensino superior.

Assim, a finalidade das fundações de apoio está direcionada para o avanço da ciência, focando a qualidade e o desenvolvimento do ensino e melhoria da extensão. A sua origem está vinculada a uma preocupação com ação social na medida em que trazem demandas sociais para dentro da universidade e promovem a difusão do conhecimento, sendo a interface da universidade com os órgãos de fomento e a comunidade em geral (COELHO e COELHO, 2006; ROCHA, 2012).

De acordo com Dalto (2014), essas organizações assumem uma característica híbrida, pois apesar de serem criadas com personalidade jurídica privada, se sujeitam às rígidas normas da Administração Pública. São obrigadas a prestar contas da execução de convênios, contratos, acordos e demais ajustes aos entes financiadores, submetem-se ao controle do órgão máximo da instituição de ensino da entidade contratante e, ainda, estão subordinadas ao controle finalístico pelo órgão governamental competente. 
A aplicação dos recursos oriundos das atividades da própria fundação e dos projetos de terceiros sob seu controle requerem um processo frequente de tomada de decisão. Ao mesmo tempo essas entidades sofrem controle constante, tanto de origem externa como interna, tornando-se, em vista disso, usuários em potencial das informações contábeis, seja para observância de cumprimento de legislação, seja para prestação de contas (SANTOS, DEODORO, PAULA E COLAUTO, 2008; SANTOS, 2008).

\subsection{A Contabilidade Aplicada ao Terceiro Setor}

A contabilidade pode ser definida como a ciência do controle econômico do patrimônio de uma entidade. Como esse controle é caraterizado pela geração de informações quantitativas, a contabilidade é objetivamente um sistema de informação que controla o patrimônio da entidade (PADOVEZE, 2012).

Nessa linha, Silva (2013) afirma que a contabilidade, cumprindo seu papel enquanto ciência, possuí como principal finalidade a mensuração patrimonial e sua exposição sob a forma de informação, e, neste intuito, pode viabilizar e dar sustentabilidade ao objetivo social das organizações, além de proporcionar diretrizes àquelas que são detentoras de metas coletivas: as Organizações do Terceiro Setor.

No tocante a contabilidade, Jin (2010) esclarece que há distinções entre as organizações empresarias e as organizações sem fins lucrativos, que decorrem, em parte, a partir de seus diferentes objetivos. Para o autor, em organizações comerciais, o objetivo é combinar receitas e despesas para medir rentabilidade, enquanto nas organizações sem fins lucrativos, a prestação de contas das atividades e os benefícios tributários são os principais objetivos da contabilidade.

Contribuindo com a temática, Costa, Parker e Andreaus (2014) ampliam esse entendimento ao disciplinarem que quando se trata de contabilidade e terceiro setor, deve-se considerar o equilíbrio econômico e financeiro dessas entidades como um requisito para a sobrevivência em longo prazo. Nesse sentido, prosseguem os autores, uma orientação para a criação de valor social não indica que se deve ignorar estratégias para gerar superávits e fluxo de caixa; em contrário, deve-se constantemente criar valor para sobreviver ao longo do tempo e garantir que essas organizações sejam capazes de continuar com a sua missão.

Reconhecendo a importância da contabilidade na gestão das OTS, o Conselho Federal de Contabilidade (CFC), na qualidade de órgão regulador da contabilidade no Brasil, disciplinou em 1999 Normas Brasileiras de Contabilidade direcionadas as Fundações (NBC T 10.04), para as Entidades Sindicais e Associações de Classe (NBC T 10.18) e, em 2000, emitiu a NBC T 10.19, voltada a Entidades sem Finalidade de Lucros.

Essas normas foram revogadas em 2012 e a Interpretação ITG n $^{\circ} 2002$ passou a estabelecer critérios e procedimentos específicos de avaliação, de reconhecimento das transações e variações patrimoniais, de estruturação das demonstrações contábeis e as informações mínimas a serem divulgadas em notas explicativas da entidade sem finalidade de lucros.

Desta forma, a contabilidade está presente na administração das OTS: (i) na prestação de contas; (ii) na análise de relatórios financeiros; (iii) nas técnicas de planejamento e controle de gestão e (iv) na promoção da sustentabilidade da organização (Olak e Nascimento, 2006; Silva 2013).

O estudo de Santos (2010), parcialmente replicado nesta pesquisa, explora três aspectos essenciais relacionados com as práticas contábeis das organizações sem fins lucrativos, conforme discriminado na Tabela 1.

R. Cont. Ufba, Salvador-Ba, v. 9, n. 3, p. 171 - 184, set-dez 2015 
Tabela 1: Aspectos contábeis relacionados às organizações sem fins lucrativos

\begin{tabular}{|c|l|}
\hline \multicolumn{2}{|c|}{ Aspectos contábeis das organizações sem fins lucrativos } \\
\hline $\begin{array}{c}\text { Demonstrações contábeis que devem } \\
\text { ser elaboradas pelas entidades sem fins } \\
\text { lucrativos. }\end{array}$ & $\begin{array}{l}\text { Balanço Patrimonial; Demonstração do Resultado do Período; } \\
\text { Demonstração das Mutações do Patrimônio Líquido; Demonstração } \\
\text { dos Fluxos de Caixa e as Notas Explicativas. }\end{array}$ \\
\hline Prestação de Contas - A quem dirigir. & Financiadores; Governo; Doadores e beneficiários. \\
\hline Artefatos internos. & Sistemas de Custos; Orçamento e Planejamento. \\
\hline
\end{tabular}

Fonte: Adaptado de Santos (2010).

Outros estudos envolvendo as práticas contábeis das OTS demonstram a utilização ainda insipiente da contabilidade em algumas entidades desse segmento (CASTRO et al., 2014).

Cruz (2010, p. 3) ao estudar 124 entidades qualificadas como OSCIP, para entender o valor da informação contábil para doadores em suas decisões de investimento, pondera que "no Brasil, a publicação de relatórios contábeis das organizações do terceiro setor não tem sido prática comum, ademais, a iniciativa do Ministério da Justiça de divulgar dados oriundos da contabilidade dessas entidades é recente“.

Piza et al. (2012) ao compararem os procedimentos contábeis de organizações sociais da cidade de São Paulo com as Normas Brasileiras de Contabilidade, observaram que a baixa profissionalização da gestão, associada à ausência de um Contador na maioria daquelas organizações, sugere que as NBCTs não são fielmente cumpridas, e pouca atenção é dada à precisão das demonstrações contábeis.

Mario et al. (2013) analisaram a utilização de instrumentos de contabilidade gerencial por ONG's localizadas em municípios de Minas Gerais. Neste estudo os autores constataram que em geral, apesar do muito que se avançou e de casos de sucesso com efetivas melhorias, a maioria dessas entidades ainda necessita desenvolver seus sistemas de informações contábeis e o uso dos instrumentos em si.

Silva (2013) ao analisar a conformidade das demonstrações contábeis das mantenedoras de Instituições de Ensino Superior do Sul de Minas Gerais, constatou que essas entidades elaboram todas as demonstrações definidas pelas normas contábeis, porém utilizando ainda nomenclaturas utilizadas em demonstrações de entidades com fins lucrativos, e ainda, não evidenciam todos os complementos às demonstrações, dispostos sob a forma de notas explicativas.

Santos, Laureano e Machado (2014) ao estudarem a contabilidade de gestão no terceiro setor em instituições particulares de solidariedade social de Portugal, verificaram que mesmo sendo possível obter informações que identifiquem situações deficitárias, os sistemas de contabilidade de gestão implementados não garantem o suporte à tomada de decisão naquelas entidades.

\section{PROCEDIMENTOS METODOLÓGICOS}

O presente estudo pode ser classificado como descritivo, quantitativo e de campo. Quanto ao levantamento dos dados adotou-se como instrumento de coleta de dados o questionário utilizado no estudo de Santos (2010). A escolha do instrumento foi motivada por suas validações já realizadas, além deste ter sido concebido por meio de vasta pesquisa bibliográfica e ser direcionado às entidades sem fins lucrativos, objeto da presente pesquisa.

Cabe destacar que foram realizados alguns ajustes no instrumento original para os fins deste trabalho, buscando maior inserção com as organizações estudadas, assim foram realizadas as seguintes modificações: (i) as opções da questão relacionada à área de atuação

R. Cont. Ufba, Salvador-Ba, v. 9, n. 3, p. 171 - 184, set-dez 2015 
da organização, as quais foram modificadas considerando o disposto na Lei n. 8.958/1994 e; (ii) a questão que procura averiguar para quem as organizações prestam contas, também em conformidade com a Lei já citada.

Ainda em relação ao questionário, acrescentou-se: (i) duas alternativas nas assertivas que buscam verificar os tipos de documentos que são elaborados para prestação de contas das fundações a terceiros, e; (ii) duas questões: uma para capturar o estado da federação e outra para capturar qual o ente federativo que a fundação está ligada, devido a amostra selecionada para a presente pesquisa. Por último, foi retirada a assertiva sobre a existência de escrituração contábil, pois tal constatação é verificada indiretamente em outras questões do instrumento.

$\mathrm{O}$ instrumento de coleta de dados é segregado em cinco blocos de questões. Todas as assertivas são fechadas, com algumas utilizando a escala de intensidade do tipo Likert, com cinco níveis variando de " 1 " (discordo plenamente) a " 5 " (concordo plenamente). Os blocos do instrumento estão assim organizados: (i) caracterização do respondente; (ii) caracterização da organização; (iii) aspectos relativos aos beneficiados e interessados da organização; (iv) aspectos relativos às práticas de contabilidade e à prestação de contas da organização; e (v) aspectos relativos aos artefatos internos utilizados para tomada de decisão.

A população selecionada nesta pesquisa é constituída pelas fundações de apoio das universidades públicas do sul do país. Atualmente, existem 31 instituições de ensino públicas nos estados do Paraná, Santa Catarina e Rio Grande do Sul e 19 fundações de apoio.

Para a coleta de dados, preliminarmente, foram contatados os contadores de cada fundação de apoio, explicando a pesquisa e requisitando sua participação. Após o contato, foi enviado e-mail aos respondentes requisitando a participação no estudo, por meio do link do questionário, o qual foi disponibilizado no formato on-line na plataforma SurveyDox®, software específico para questionários web. O tempo de coleta de dados ocorreu no período de 17/04/2015 até 28/05/2015. Da população composta de 19 fundações, foi obtido a resposta de dez, ou seja, 52,63\% da população.

Como tratamento estatístico dos dados utiliza-se: estatística descritiva e univariada, e por último, análise de referência cruzada (Crosstab).

\section{ANÁLISE DOS RESULTADOS}

A análise de resultados está subdivida em cinco partes, as quatro primeiras partes obedecem a estrutura do questionário aplicado, sendo: (i) caracterização da amostra; (ii) aspectos relativos aos beneficiados e interessados da organização; (iii) aspectos relativos às práticas de contabilidade e à prestação de contas da organização; (iv) aspectos relativos aos artefatos internos e (v) análises de referência cruzadas.

\subsection{Caracterização da Amostra}

A primeira parte do instrumento aplicado é composto por questões de caracterização do respondente e da organização. Neste sentido, primeiramente são sintetizadas as características organizacionais das dez fundações participantes da amostra:

- Dentre as fundações participantes, todas existem há mais de 5 anos;

- Das fundações participantes, 5 (50\%) são do Rio Grande do Sul, duas de Santa Catarina e três do Paraná;

- Quanto ao ente federativo, oito delas (80\%) são federais e apenas duas estaduais;

R. Cont. Ufba, Salvador-Ba, v. 9, n. 3, p. 171 - 184, set-dez 2015 
- Com relação ao número de funcionários, nove delas (90\%) possuem mais de 15 funcionários, e apenas uma possui entre 5 a 10 funcionários;

- Também foi questionado as fundações o número de voluntários existentes nas fundações, e observa-se que $50 \%$ da amostra possui mais de 15 voluntários e $40 \%$ até cinco voluntários;

- Quanto a área de atuação das fundações, que pode ser mais que uma, observa-se que as áreas de atuação em ordem decrescente são: "Desenvolvimento institucional, científico e tecnológico" (9); "Extensão" (8); "Pesquisa" (8); "Ensino" (7) e "Estímulo à Inovação" (5).

De acordo com as caracterizações organizacionais, pode-se observar que a amostra compreende fundações consolidadas, predominantemente federais, com dezenas de funcionários e voluntários. Além disso, as áreas de atuações das fundações estão alinhadas às funções básicas das instituições de ensino superior, sendo ensino, pesquisa e extensão, os quais repercutem em um segundo estágio à inovação e o desenvolvimento tecnológico, científico e institucional.

Além das assertivas citadas de caracterização da organização, a missão declarada/explícita também foi pesquisada, que de acordo com Santos (2010), a razão da existência das organizações do terceiro setor passa pela declaração explícita de sua missão. A análise das assertivas relacionadas a missão, primeiramente observa-se que oito $(80 \%)$ fundações afirmaram possuir uma missão declarada e explícita. Na pesquisa de Santos (2010), com as organizações sem fins lucrativos de Curitiba-PR, 96,67\% delas afirmaram a existência da missão declarada, percentual maior que o observado no presente estudo.

Dentre as fundações que possuem missão declarada (8), foram investigadas questões que permitissem verificar a aderência da missão com os projetos desenvolvidos pela entidade, relevando alguns aspectos: $75 \%$ consideram a missão curta e com foco bem direcionado; $50 \%$ nem concordaram e nem discordaram que a missão seja clara e facilmente compreendida; $88 \%$ consideram a missão suficientemente abrangente; $100 \%$ consideram que a missão fornece direção para execução das tarefas de forma acertada; todos consideram que a missão está adequada às competências da fundação; $88 \%$ consideram que a missão inspira o compromisso da fundação; porém, $75 \%$ acreditam que a missão deveria ser revista.

Cabe aqui citar as respostas obtidas com relação a missão da fundação, observa-se que os respondentes em sua maioria ponderaram de forma positiva a missão, com exceção da necessidade dessa ser revisada $(75 \%)$. Tal motivo pode ser explicado ao fato de metade dos respondentes não terem opinado que a missão seja clara e facilmente compreendida.

$\mathrm{Na}$ sequência, foram indagados aos respondentes assertivas que buscaram a caracterização deles próprios, resultando nas seguintes informações:

- Com relação aos cargos ocupados pelos respondentes, $40 \%$ são "Presidentes, $40 \%$ Contadores, $10 \%$ Controller e $10 \%$ Gerente;

- Quanto a faixa etária, 40\% estão entre 26 e 35 anos, e o restante possuem mais de 35 anos;

- O tempo de atuação na fundação também foi alvo de análise, e observa-se que $70 \%$ estão há mais de cinco anos, com o restante entre o tempo de 1 a 5 anos;

- Com relação ao grau de instrução, observa-se que todos possuem ensino superior, com $70 \%$ com o título de especialista. 
Resumidamente, observa-se que os respondentes possuem cargos e formação que os qualificam a participarem da pesquisa, e ainda, em sua maioria possuem experiência na fundação a fim de possibilitar informações fidedignas ao estudo.

\subsection{Aspectos relativos aos beneficiados e interessados da organização}

Neste bloco buscou-se avaliar características com relação aos beneficiados e interessados da fundação. Primeiramente, com relação aos funcionários e voluntários, os incentivos mais intensos são primeiramente a remuneração compatível com a de outras organizações (44\%), o treinamento periódico $(25 \%)$ e a participação de palestras, simpósios, congressos que possam ampliar a visão desses clientes sobre o trabalho desenvolvido pela fundação (19\%). Na pesquisa de Santos (2010) o incentivo mais frequente não foi a remuneração, e sim a realização de reuniões periódicas com objetivo de apresentar os principais resultados obtidos $(40 \%)$, que na presente pesquisa obteve apenas $6 \%$ de representatividade.

$\mathrm{Na}$ sequência, também foi analisado o incentivo da fundação com seus parceiros e doadores. Neste ponto, observa-se que o maior incentivo é relativo a participação de palestras, simpósios, congressos que possam ampliar a visão desses clientes sobre o trabalho desenvolvido pela fundação (40\%); em segundo lugar a realização de reuniões periódicas com objetivo de apresentar os principais resultados obtidos pela fundação (30\%) e, de forma negativa, 30\% dos respondentes afirmaram a inexistência de ações de incentivo a parceiros e doadores.

A fim de avaliar se a fundação realizada pesquisa para identificar a satisfação dos beneficiados de suas ações observa-se que $50 \%$ afirmou que "nunca" é realizada tal pesquisa, e ainda, $40 \%$ afirmam que "às vezes". Tal fato pode deve ser revisto pelas fundações, pois a análise posterior às ações é de suma importância, a fim de avaliar o feedback com o objetivo de melhoria nesses processos.

O incentivo de sugestões dos funcionários, voluntários, beneficiados, doadores e financiadores por parte da fundação também foi analisado. Observa-se que os incentivos são mais latentes com os funcionários (100\%), beneficiados (90\%) e voluntários (70\%). Já para os financiadores e doadores é menor, sendo $50 \%$ e $40 \%$ respectivamente. Com relação aos funcionários e voluntários, os resultados são congruentes a pesquisa de Santos (2010). Tais dados induzem a percepção de um maior distanciamento entre a fundação e suas fontes de recursos, no que concerne ao estimulo na apresentação de propostas de melhoria.

De forma contrária aos achados de Santos (2010), que verificou que $70 \%$ das entidades monitoram as sugestões que recebem, na presente pesquisa apenas $40 \%$ realizam tal monitoramento, um fato preocupante quando considerada a necessidade de melhoria contínua necessária a todas as entidades, de acordo com Reali (2006).

\subsection{Aspectos relativos às práticas de contabilidade e à prestação de contas das fundações}

O terceiro bloco do survey busca analisar as práticas contábeis e a prestação de contas da fundação. Primeiramente, foram analisados quais relatórios são utilizados para fundação, os quais são relacionados em ordem decrescente de utilização: Balanço Patrimonial (BP) [100\%]; Demonstração do Superávit ou Déficit do Exercício (DSDE) [100\%]; Notas Explicativas (NE) [100\%]; Demonstração dos Fluxos de Caixa (DFC) [100\%]; Demonstração da Mutação do Patrimônio Social (DMPS) [100\%]; Demonstração do Valor Adicionado 
(DVA) [90\%]; Demonstração das Origens e Aplicações de Recursos (DOAR) [70\%]; e Balanço Social (BS) [60\%].

Os resultados citados indicam uma maior intensidade de uso dos relatórios citados nas fundações, quando comparadas com as entidades sem fins lucrativos de Curitiba-PR, pesquisa por Santos (2010), que obteve apenas $40 \%$ no BS, 63,3\% na DFC e 36,67\% na DVA.

Tais resultados indicam que as fundações possuem em geral uma maior aderência às demonstrações contábeis, lembrando é claro, que tal utilização muitas vezes é incentivada pela obrigatoriedade de elaboração de tais relatórios, como o BP e DSDE, por exemplo. Essa constatação também foi verificada na pesquisa de Silva (2013) que ao analisar a conformidade das demonstrações contábeis das mantenedoras de Instituições de Ensino Superior do Sul de Minas Gerais, comprovou que essas entidades elaboram todas as demonstrações definidas como obrigatórias para as OTS pelas normas contábeis.

Na sequência, também foi indagado as fundações para quem prestam contas, de modo que, em ordem as constas são prestadas para: Ministério Público [100\%]; Órgão máximo da Instituição de Ensino [100\%]; Entes financiadores [90\%]; Órgão de controle governamental competente [80\%] e Comunidade e Doadores [60\%]. Em relação aos relatórios repassados aos entes que recebem a prestação de contas das fundações esses foram sumarizados na Tabela 2.

Tabela 2 - Prestação de Contas Realizadas

\begin{tabular}{|c|c|c|c|c|c|c|c|c|c|c|}
\hline \multirow[t]{2}{*}{ Relatórios } & \multicolumn{2}{|c|}{$\begin{array}{c}\text { Entes } \\
\text { Financiadores }\end{array}$} & \multicolumn{2}{|c|}{$\begin{array}{l}\text { Órgão } \\
\text { máximo da } \\
\text { IE }\end{array}$} & \multicolumn{2}{|c|}{$\begin{array}{c}\text { Órgão } \\
\text { Controle } \\
\text { Governamental }\end{array}$} & \multicolumn{2}{|c|}{$\begin{array}{l}\text { Ministério } \\
\text { Público }\end{array}$} & \multicolumn{2}{|c|}{$\begin{array}{c}\text { Comunidade } \\
\text { e Doadores }\end{array}$} \\
\hline & Freq. & $\%$ & Freq. & $\%$ & Freq. & $\%$ & Freq. & $\%$ & Freq. & $\%$ \\
\hline $\begin{array}{r}\text { Total de fundações que } \\
\text { prestam contas }\end{array}$ & \multicolumn{2}{|c|}{9} & \multicolumn{2}{|c|}{10} & \multicolumn{2}{|c|}{8} & \multicolumn{2}{|c|}{10} & \multicolumn{2}{|c|}{6} \\
\hline Balanço Patrimonial (BP) & 3 & $33 \%$ & 6 & $60 \%$ & 4 & $50 \%$ & 10 & $100 \%$ & 5 & $83 \%$ \\
\hline $\begin{array}{l}\text { Demonstração do Superávit ou } \\
\text { Déficit do Exercício (DSDE) }\end{array}$ & 3 & $33 \%$ & 6 & $60 \%$ & 4 & $50 \%$ & 10 & $100 \%$ & 5 & $83 \%$ \\
\hline $\begin{array}{l}\text { Demonstração das } \\
\text { Aplicações de } \\
\text { (DOAR) }\end{array}$ & 3 & $33 \%$ & 4 & $40 \%$ & 3 & $37 \%$ & 7 & $70 \%$ & 1 & $17 \%$ \\
\hline Notas Explicativas (NE) & 3 & $33 \%$ & 6 & $60 \%$ & 4 & $50 \%$ & 9 & $90 \%$ & 5 & $83 \%$ \\
\hline $\begin{array}{l}\text { Demonstração dos Fluxos de } \\
\text { Caixa (DFC) }\end{array}$ & 3 & $33 \%$ & 6 & $60 \%$ & 4 & $50 \%$ & 7 & $70 \%$ & 2 & $33 \%$ \\
\hline $\begin{array}{ll}\text { Demonstração do } & \text { Valor } \\
\text { Adicionado (DVA) } & \end{array}$ & 0 & $0 \%$ & 2 & $20 \%$ & 0 & $0 \%$ & 6 & $60 \%$ & 1 & $17 \%$ \\
\hline $\begin{array}{l}\text { Demonstração da Mutação do } \\
\text { Patrimônio Social (DMPS) }\end{array}$ & 0 & $0 \%$ & 3 & $30 \%$ & 1 & $12 \%$ & 7 & $70 \%$ & 2 & $33 \%$ \\
\hline Balanço Social (BS) & 3 & $33 \%$ & 4 & $40 \%$ & 3 & $37 \%$ & 6 & $60 \%$ & 5 & $83 \%$ \\
\hline $\begin{array}{llr}\text { Formulários } & \text { e } & \text { documentos } \\
\text { próprios } & \text { dos } & \text { entes } \\
\text { financiadores } & & \\
\end{array}$ & 9 & $100 \%$ & 8 & $80 \%$ & 4 & $50 \%$ & 3 & $30 \%$ & 2 & $33 \%$ \\
\hline $\begin{array}{l}\text { Relatórios relativos a cada } \\
\text { projeto financiado }\end{array}$ & 1 & $10 \%$ & 1 & $10 \%$ & 0 & $0 \%$ & 0 & $0 \%$ & 0 & $0 \%$ \\
\hline $\begin{array}{l}\text { Relatório } \mathrm{de} \\
\text { Gestão/formulários próprios }\end{array}$ & 0 & $0 \%$ & 3 & $30 \%$ & 1 & $12 \%$ & 1 & $10 \%$ & 1 & $17 \%$ \\
\hline Sicap & 0 & $0 \%$ & 0 & $0 \%$ & 0 & $0 \%$ & 3 & $30 \%$ & 0 & $0 \%$ \\
\hline Portal da Transparência & 0 & $0 \%$ & 0 & $0 \%$ & 0 & $0 \%$ & 0 & $0 \%$ & 1 & $17 \%$ \\
\hline
\end{tabular}

Fonte: da pesquisa.

De acordo com a Tabela 2, pode-se observar que para os "Entes Financiadores" os formulários e documentos próprios destes são os mais utilizados pelas fundações prestarem

R. Cont. Ufba, Salvador-Ba, v. 9, n. 3, p. 171 - 184, set-dez 2015 
constas. Já para o "Órgão máximo da IE" e o "Órgão de Controle Governamental” observa-se além dos formulários e documentos próprios, o BP, DSDE, NE e DFC são relatórios bastante utilizados. A prestação de contas para o "Ministério Público" é essencialmente as demonstrações contábeis. Por último, para a "Comunidade e Doadores", observa-se o uso do $\mathrm{BP}, \mathrm{DSDE}$, NE e o BS, que não é tão utilizado para os outros entes.

Na sequência, também foi verificada a frequência de preparação dos relatórios citados na Tabela 2. Essencialmente tais relatórios são elaborados de forma mensal (30\%) e anual (40\%), de modo que, $30 \%$ responderam não existir regularidade em suas elaborações.

A última assertiva do terceiro bloco remete-se ao uso das informações contábeis, sendo que $70 \%$ utilizam para fins fiscais; $70 \%$ também utilizam para controle das operações da fundação; e 30\% utilizam para prestar contas para os financiadores. Os resultados são congruentes com a pesquisa de Santos (2010), com exceção do uso para fins fiscais, que obteve um percentual de apenas $16,67 \%$.

Entretanto, os resultados contrapõem-se, em parte, às distinções apontadas por Jin (2010) quando o autor afirma que a contabilidade nas OTS possui, como um de seus principais objetivos, a prestação de contas das atividades, e observa-se que menos de $50 \%$ da amostra, indica a utilização da informação contábil para esse fim.

Tal resultado pode revelar uma falha de percepção de alguns respondentes em relação à informação gerada pela contabilidade, visto que essa é um dos elementos que apoia e evidencia a prestação de contas, uma vez que a "prestação de contas é o conjunto de documentos e informações disponibilizados pelos dirigentes às partes interessadas, de forma a possibilitar a apreciação, conhecimento e julgamento das contas e da gestão dos administradores das entidades." (CFC, 2008).

Já em relação ao uso da contabilidade para fins fiscais, revela-se um alinhamento ao estudo de Jin (2010), visto que para o autor os benefícios tributários é o outro principal objetivo da contabilidade nas organizações sem fins lucrativos.

\subsection{Aspectos Relativos aos Artefatos Internos}

O quatro e último bloco refere-se aos aspectos relativos aos artefatos internos utilizados pelas fundações, essencialmente sob três aspectos: custos, planejamento e orçamento, similar a pesquisa de Santos (2010).

A primeira assertiva refere-se ao cálculo do custo dos serviços prestados pela fundação. Observa-se que, apenas $40 \%$ das fundações calculam custo, resultado este similar ao de Santos (2010), com 45\%. Para os que calculam o custo, não foi detectada uma forma de custeio predominante.

Com relação ao planejamento, observa-se que apenas $10 \%$ não faz planejamento, ou seja, $90 \%$ das fundações fazem planejamento, sendo que $80 \%$ realizam apenas com o planejamento operacional, não utilizando o plano estratégico, que inclui o plano financeiro e institucional de longo prazo.

$\mathrm{Na}$ sequência, algumas assertivas analisam o uso do orçamento pelas fundações. Primeiramente, observa-se que todas as fundações pesquisadas utilizam o orçamento, com $10 \%$ afirmando utilizar em alguns projetos, porém $90 \%$ utilizam para todos os seus projetos. Como se observa, a utilização é intensa, e ainda, difere dos achados Santos (2010), que apenas $56,67 \%$ afirmaram utilizar o orçamento em todos os seus projetos.

Ainda com relação ao orçamento, observa-se que além do uso intenso por parte das fundações, $90 \%$ delas realizam a confrontação das metas estabelecidas com o executado, a fim de avaliar e/ou readequar o orçamento. Por último, quanto a divulgação das metas 
estabelecidas no orçamento, $50 \%$ afirmaram que divulgam apenas para membros do conselho, $30 \%$ informaram que não divulgam e $20 \%$ divulgam para membros do conselho, funcionários e voluntários.

De acordo com o exposto, observa-se que as fundações não utilizam intensamente as ferramentas de custeio, porém tanto o planejamento quanto o orçamento são bastante utilizados pelas entidades, corroborando os dados encontrados pelo estudo de Mario et al (2013) que constataram que a maioria das ONG's localizadas em municípios de Minas Gerais não calcula o custo e que o orçamento, por sua vez, é realizado na grande maioria dos projetos.

Por fim, ainda em relação aos custos, os dados encontrados, sugerem um alinhamento aos achados revelados pela pesquisa de Santos, Laureano e Machado (2014, p. 82 e 85), na qual os autores constataram que o gestor da OTS percebe a utilidade e importância da informação contábil, entretanto, alguns "concordam com a existência de informação suficiente como causa do não desenvolvimento do sistema de custeio [...] razão pela qual não há um tão elevado desenvolvimento do sistema de contabilidade de gestão que pode ser explicado pela não percepção do atual sistema como obsoleto".

\subsection{Análises de referências cruzadas (Crosstab)}

Para Malhotra (2001) as Crosstabs (tabulações cruzadas) são uma técnica estatística que descreve duas ou mais variáveis, simultaneamente, originando tabelas que refletem a distribuição conjunta de duas ou mais variáveis com um número limitado de categorias ou valores distintos. Neste sentido, as tabulações cruzadas foram utilizadas a fim de localizar importantes características nos elementos da amostra.

A primeira análise cruzada refere-se à função do respondente com sua idade. Observase que nenhum Presidente possui idade menor que 35 anos. Já os contadores, observa-se que $50 \%$ (2 de 4) possui idade menor que 35 anos. Tal informação indica que os cargos de presidentes nas organizações vêm sendo desempenhados por pessoas de maior experiência, o que não ocorre para os cargos de Contadores.

A relação entre o número de voluntários com o incentivo da fundação para que estes apresentem sugestões também foi alvo de análise. Observa-se uma tendência de maior incentivo por sugestões para aquelas fundações com mais cinco voluntários (acima de 80\%). Já para as fundações com até cinco voluntários, observa-se que apenas metade ( 2 de 4$)$ incentivam seus voluntários a apresentarem sugestões.

$\mathrm{Na}$ sequência, ainda com o número de funcionários, foi cruzada tal assertiva com a prestação de contas por parte da fundação com a comunidade e doadores. Observa-se que $100 \%$ das fundações com mais de 5 voluntários (5) prestam contas para a comunidade e doadores. Em contrapartida, 75\% das que possuem até 5 voluntários (3 de 4) não prestam contas para a comunidade e doadores. Tal fato pode ser um indicativo de que a maior relação entre fundações e comunidade, por vezes, pela prestação de contas, traga um maior número de voluntários para a fundação.

\section{CONCLUSÃO}

A presente pesquisa teve origem no interesse de investigar se o uso da contabilidade nas fundações de apoio das universidades públicas é ainda restrito, como apontam alguns estudos de caso que discutem as práticas e procedimentos contábeis das OTS. 
Sendo a contabilidade ferramenta indispensável para aumentar a transparência da gestão, a investigação teve, ainda, como elemento desencadeador, a recente discussão acerca da falta de transparência nas relações intermediadas pelas fundações de apoio. Desta forma, colocou-se como questão de pesquisa: Quais são as práticas de contabilidade das fundações de apoio a instituições públicas de ensino superior no Brasil?

Identificou-se, então, que o BP; a DSDE; as NE; a DFC e a DMPS, são elaboradas por $100 \%$ das fundações pesquisadas e que em sua totalidade as fundações prestam contas ao Ministério Público e ao Órgão máximo da Instituição de Ensino apoiada.

É importante evidenciar, também, que $70 \%$ das fundações utilizam a contabilidade para fins fiscais e para controle das operações da organização; e, por outro lado, apenas 30\% fazem uso das informações contábeis para prestar contas aos financiadores.

Observa-se, ainda, que $90 \%$ das fundações elaboram planejamento e utilizam o orçamento para todos os seus projetos, prática que não surpreende pela frequência, visto que tais artefatos são exigidos nos planos de trabalhos apresentados pela organização quando de seu interesse em firmar convênios e contratos para a operacionalização de seus projetos.

O presente estudo evidencia, à luz dos elementos obtidos em campo, que o uso da contabilidade nessas organizações ainda é direcionado a atender a legislação e as normas vigentes, consideração esta que se apoia na não integralidade de entidades que prestam contas para a comunidade e doadores e pela não elaboração, em $100 \%$ das fundações, de demonstrações não obrigatórias, em particular àquela voltada a comunidade em geral, o BS, e, finalmente, pelo fato das fundações em sua minoria (40\%) calcularem custo, ferramenta de apoio à análise gerencial.

Percebe-se, ainda, que há um limite de reconhecimento sobre o uso da contabilidade no que se refere à prestação de contas visto que as informações financeiras oriundas do sistema contábil permeiam toda prestação de contas de qualquer organização e menos da metade dos respondentes captam corretamente esse evento.

Assim, a pesquisa de campo revelou que o desafio está: i) em eliminar falsas percepções sobre o uso e utilidade da informação contábil no terceiro setor e ii) conscientizar os gestores das OTS sobre a relevância da informação que pode ser produzida pela contabilidade no que se refere a sustentabilidade dessas organizações.

Finalmente, se faz necessário destacar a importância dessas organizações na realização de projetos executados com recursos transferidos pelos entes governamentais, na medida em que dispõem de maior autonomia e flexibilidade administrativa em razão de sua natureza privada. Dessa forma, essas organizações contribuem para o desenvolvimento econômico e social do país, por meio do apoio à implementação das políticas públicas educacionais, retornando o investimento cientifico, público e privado, à sociedade em geral.

Diante dessa importância e a fim de transformar, a hoje transparência nominal, adotada por obrigatoriedade legal, em transparência efetiva, sugere-se o desenvolvimento de instrumentos complementares ou alternativos de evidenciação, de acesso pelos portais de transparência das fundações, que englobem os objetos dos convênios/contratos, sua finalidade acadêmica e as despesas relacionadas aos projetos, notadamente quanto aos pagamentos de serviços de pessoas físicas e aquisição de equipamentos e material permanente, bem como o percentual de participação dessas despesas no total desembolsado no projeto.

Do proposto, percebe-se a importância crítica das informações contábeis, visto que as despesas podem ser conhecidas por meio do ciclo contábil, desde o reconhecimento das transações até a elaboração de suas demonstrações. 
Destarte, espera-se que as variáveis observadas possam apoiar novos estudos correlatos e, também, aos que se proponham a fomentar o uso da contabilidade nas OTS para além dos ditames obrigatórios da legislação.

\section{REFERÊNCIAS}

ALVES, C. V. e SLOMSKI, V. Organizações da sociedade civil de interesse público e termos de parceria: um estudo sobre o Processo de avaliação de resultados dos projetos sociais desenvolvidos com recursos governamentais no Brasil. 2006. Disponível em: $<$ http://www.congressousp.fipecafi.org/web/artigos62006/391.pdf. >. Acesso em: 26 mar. 2015.

ALVES, A.M.S e AZEVEDO, M.L.N. Fundações de apoio à universidade: uma discussão sobre o conflito entre o público e o terceiro setor. Atos de Pesquisa em Educação, v. 2, n. 3, p. 486-507, set./dez. 2007.

ANÍBAL, F., VALÉRIO, M.B., L., GOIS, A., HELAL FILHO, W., IRION, A., TREZZI, H., LOPES, R., M., R., SACOMAN, A.C, SALDAÑA, P., HANGAI, L.A., RINALDI, M. e VIEIRA, R. Negócios entre universidades públicas e empresas são alvo de investigação. 2015. Disponível em: < http://oglobo.globo.com/sociedade/educacao/negocios-entreuniversidades-publicas-empresas-sao-alvo-de-investigacao-15845818>. Acesso em: 15 abr. 2015.

BRASIL. Ministério da Educação. Fundações de apoio - apresentação. Disponível em < http://portal.mec.gov.br/index.php?option=com_content\&view=article\&id=12508\&Itemid=8 27>. Acesso em: 28 mar. 2015.

BRASIL. Lei n. 8.958, de 20 de dezembro de 1994. Dispõe sobre as relações entre as instituições federais de ensino superior e de pesquisa científica e tecnológica e as fundações de apoio e dá outras providências. Diário Oficial [da] República Federativa do Brasil, Brasília, DF, dez. 1994, Seção 1.

BRASIL. Lei. N. 10.406, de 10 de janeiro de 2002. Institui o Código Civil. Diário Oficial [da] República Federativa do Brasil, Brasília, DF, jan. 2002, Seção 1.

CASTRO, V.R., DONEGA, P.H.C.C., GOMES, G.S., RECH, I.J., COSTA, P.S. Instrumentos contábeis e gerenciais nas pesquisas relacionadas a organizações do terceiro setor. In: CONGRESSO USP DE INICIAÇÃO CIENTÍFICA EM CONTABILIDADE, 11, 2014, São Paulo. Novas perspectivas na ciência contábil. Disponível em: < http://www.congressousp.fipecafi.org/web/artigos142014/352.pdf>. Acesso em: 10 abr. 2015.

COELHO, S. C. N. e COELHO, E. J. A relação entre as fundações de apoio e as instituições federais de ensino superior, em face da Lei ${ }^{\circ}$ 8.958/1994. Revista IOB de Direito Administrativo, São Paulo, v. 1, n. 12, p. 41-83, dez. 2006.

CONSELHO FEDERAL DE CONTABILIDADE. Resolução CFC n. 1409 de 21 de setembro de 2012. Aprova o ITG 2002 - Entidades sem fins lucrativos. Diário Oficial [da] República Federativa do Brasil, Brasília, 2002.

R. Cont. Ufba, Salvador-Ba, v. 9, n. 3, p. 171 - 184, set-dez 2015 
. Manual de procedimentos contábeis para fundações e entidades de interesse social. Disponível em: <http://portalcfc.org.br/wordpress/wpcontent/uploads/2013/01/Manual_procedimentos2008.pdf>. Acesso em: 12 jun. 2015.

COSTA, E., PARKER, L. D. e ANDREUS, M. The rise of social and non-profit organizations and their relevance for social accouting studies. In E. Costa, L. D. Parker e M., Andreaus (ed.). Accountability and Social Accounting for Social and Non-profit Organizations, v. 17, jul. 2014.

CRUZ, C. V. O. A. A relevância da informação contábil para os investidores sociais privados de entidades do terceiro setor no brasil: uma investigação empírica. 2010. Disponível em: <http://www.teses.usp.br/teses/disponiveis/12/12136/tde-24062010104557/pt-br.php>. Acesso em: 17 mar. 2015.

CUNHA, J.H.C. e MATIAS-PEREIRA, J. Captação de recursos no terceiro setor: fatores estratégicos para divulgação de informações. Revista Contemporânea de Contabilidade, v. 9, n. 18, p. 83-102, 2012.

DALTO, C. C. Execução de recursos de convênio entre fundações de apoio e universidades federais no Brasil: um estudo dos acórdãos do Tribunal de Contras da União. Dissertação de Mestrado do Programa de Pós-Graduação em Ciências Contábeis da FUCAPE. 2011, $118 \mathrm{f}$.

JIN, Z. Accounting for nonprofit organizations: a case study of British Red Cross. 2010. Disponível em:

<http://brage.bibsys.no/xmlui/bitstream/handle/11250/168893/1/Jin\%202010.pdf >. Acesso em: 18 maio 2015.

LAFFIN, M., BORBA, J.A. e CRUZ, F. Contabilidade e organizações do terceiro setor. Katálisys, v. 5, n. 2, p. 133-139, jul./dez. 2002.

MARIO, P.C., ALVES, A.D.F., CARMO, J.P.S., SILVA, A.P B. e JUPETIPE, F.K. N. A utilização de instrumentos de contabilidade gerencial em entidades do terceiro setor.

Sociedade, Contabilidade e Gestão, Rio de Janeiro, v. 8, n. 1, p. 64-79, jan./abr. 2013.

MALHOTRA, N. Pesquisa de marketing: uma orientação aplicada. 3 ed. Porto Alegre: Bookman, 2001.

MIRANDA, K.J. (2009). A inteligência competitiva e seu impacto em organizações do terceiro setor. Revista Terceiro Setor, v. 3, n. 1, p. 04-11, 2009.

OLAK, A. e NASCIMENTO, D.T. Contabilidade para entidades sem fins lucrativos (Terceiro Setor). São Paulo: Atlas, 2006.

PADOVEZE, C.L. Contabilidade Empresarial e Societária. Curitiba: IESDE, 2012. 
PIZA, C.T., MEGLIORINI, E., PARISI, C. e GALLO, M.F. A aderência das práticas contábeis das entidades do terceiro setor às normas brasileiras de contabilidade: um estudo multicaso de entidades do município de São Paulo-SP. Revista de Contabilidade do Mestrado em Ciências Contábeis da UERJ, Rio de Janeiro, v. 17, n.3, p. 78-97, set./dez. 2012.

REALI, L.P.P. Aplicação da Técnica de Eventos Kaizen na Implantação de Produção Enxuta: estudo de casos em uma empresa de autopeças. Dissertação (Mestrado) - Escola de Engenharia de São Carlos, Universidade de São Paulo, São Carlos, 2006, 101p.

ROCHA, J.C. O papel das Fundações de Apoio no Contexto das Universidades Públicas no Brasil. Âmbito Jurídico, Rio Grande, n. 100, maio 2012.

SALOMON, L.M. e ANHEIER, H. K. Social origins of civil society: explaininf the nonprofit sector cross-nationally. 1996. Disponível em: < http://ccss.jhu.edu/wpcontent/uploads/downloads/2011/09/CNP_WP22_1996.pdf>. Acesso em: 16 mar 2015.

SANTOS, C.A. Práticas de Contabilidade das Organizações sem fins lucrativos de Curitiba. Dissertação de Mestrado do Programa de Pós-Graduação em Contabilidade e Finanças da UFPR. 2010, 112 f.

SANTOS, C.C.R. Uma avaliação de resultados dos editais temáticos de segurança pública da Fundação de Amparo à Pesquisa do Estado da Bahia (FAPESB), entre 2004 e 2006. Dissertação de Mestrado do Programa de Pós-Graduação em Administração da UNIFACS. 2008, $118 \mathrm{f}$.

SANTOS, D.P, DEODORO, P.A., PAULA, H.C. e COLAUTO, R.D. Demonstração de valor adicionado: aplicação em uma instituição do terceiro setor de Minas Gerais. Enfoque, UEM-Paraná, v. 27, n. 3, p. 45-56, 2008.

SANTOS, M.R.C, LAUREANO, R.M.S. e MACHADO, M.J. Contabilidade de gestão no terceiro setor: estudo empírico em instituições particulares de solidariedade social. Tourism \& Management Studies, n. 10, p. 79-87, 2014.

SILVA, G.C. Terceiro setor e evidenciação contábil: um estudo das demonstrações contábeis das entidades do ensino superior do sul de Minas Gerais. In: Congresso de Excelência em Gestão, 9, 2013, Rio de Janeiro, RJ.

SILVEIRA, D. Evidenciação contábil de fundações privadas de educação e pesquisa: uma análise da conformidade das demonstrações contábeis de entidades de Santa Catarina. Dissertação de Mestrado - UFSC, 2007, 133 f.

R. Cont. Ufba, Salvador-Ba, v. 9, n. 3, p. 171 - 184, set-dez 2015 